\title{
Drenaje percutáneo con catéter del neumotórax en pacientes con COVID-19
}

\author{
Percutaneous catheter drainage of pneumothorax in patients \\ with COVID-19
}

\begin{abstract}
Juan Carlos Valencia ${ }^{1} \mathbb{D}$, Román José Zamarriego ${ }^{2}$, Mónica Bejarano ${ }^{3} \mathbb{D}$, Leonardo Arzayuz ${ }^{4}$
Médico, FACS, especialista en Cirugía general y Cirugía Mínimamente Invasiva; director, TechHealth Foundation Colombia; Cirujano General, Clínica Nueva de Cali, Clínica DESA y Clínica Farallones. Cali, Colombia.

2 Médico, especialista en Cirugía general y Cirugía de Tórax, Clínica Nueva de Cali, Clínica DESA, Clínica Farallones, Clínica Amiga, Cali, Colombia

3 Médico, especialista en Cirugía general, magíster en Epidemiología; Sección de Cirugía de Trauma y Emergencias, Departamento de cirugía, Fundación Valle del Lili.

4 Fisioterapeuta, especialista en Fisioterapia Cardiopulmonar, Unidad de Cuidado Intensivo, Clínica Farallones, Cali, Colombia
\end{abstract}

\section{Resumen}

Introducción. La transmisión del SARS-CoV-2 principalmente se da por gotas y contacto cercano con las personas infectadas, pero los aerosoles parecen ser también una fuente de infección. El neumotórax espontáneo o secundario puede presentarse en pacientes con COVID-I9, ayudado por patologías de base como la enfermedad pulmonar obstructiva crónica. Es necesario garantizar procedimientos seguros para los pacientes y buscar todas las medidas posibles para la protección del personal de la salud, por eso el drenaje de neumotórax con catéter pleural en lugar de sonda de toracostomía puede ser una de ellas.

El objetivo de este estudio es presentar a los cirujanos una alternativa a la toracostomía tradicional, mediante la utilización de catéteres de menor diámetro, para la resolución de la ocupación pleural.

Aspectos Técnicos. Se presenta el protocolo para inserción segura de un catéter pleural para el drenaje de neumotórax, mediante un sistema completamente cerrado, y se dan recomendaciones sobre el uso de filtros virales y solución viricida en el sistema de drenaje pleural conectado al catéter.

Conclusión. El estado de pandemia por COVID-I9 y el riesgo que representa para los profesionales de la salud la exposición a fuentes de transmisión durante procedimientos generadores de aerosoles, hace que se deban extremar las medidas para evitar el contagio.

Palabras clave: SARS-CoV-2; COVID-19; pandemia; neumotórax; toracostomía; drenaje pleural; catéter pleural.

Fecha de recibido: 30/06/2020 - Fecha de aceptación: 06/07/2020

Correspondencia: Juan Carlos Valencia S., Avenida Roosevelt \# 39-25 Oficina 805, Cali, Colombia. Teléfono: 3174018719

Correo electrónico: juancarlosvalencia@thf.com.co

Citar como: Valencia JC, Zamarriego RJ, Bejarano M, Arzayuz L. Drenaje percutáneo con catéter del neumotórax en pacientes con COVID-19. Rev Colomb Cir. 2020;35:404-13. https://doi.org/10-30944/20117582.772

Este es un artículo de acceso abierto bajo una Licencia Creative Commons - BY-NC-ND https://creativecommons.org/licenses/by-ncnd/4.0/deed.es 


\begin{abstract}
Introduction. The transmission of SARS-CoV-2 mainly occurs by drops and close contact with infected people, but aerosols also seem to be a source of infection. Spontaneous or secondary pneumothorax can occur in patients with COVID-I9, helped by underlying pathologies such as chronic obstructive pulmonary disease. It is necessary to guarantee safe procedures for patients and to seek all possible measures for the protection of health personnel, so drainage of pneumothorax with a pleural catheter instead of a thoracostomy tube may be one of those. The objective of this study is to present surgeons with an alternative to traditional thoracostomy, using smaller diameter catheters, to resolve pleural occupancy.

Technical aspects. The protocol for the safe insertion of a pleural catheter for pneumothorax drainage is presented, using a completely closed system, and recommendations are given on the use of viral filters and viricidal solution in the pleural drainage system connected to the catheter.

Conclusions. The state of the COVID-I9 pandemic and the risk that exposure to sources of transmission sources during aerosol-generating procedures represents for health professionals means that extreme measures must be taken to avoid contagion.
\end{abstract}

Key words: SARS-CoV-2; COVID-I9; pandemic; pneumothorax; thoracostomy; pleural drainage; pleural catheter.

\section{Introducción}

A fines de diciembre de 2019 se notificó en $\mathrm{Wu}$ han, provincia de Hubei, República Popular de China, un caso de neumonía no identificada, cuyas características clínicas fueron muy similares a las de la neumonía viral. Después del análisis de muestras respiratorias, los expertos de los Centros de Control de Enfermedades de la República Popular China declararon que la neumonía, más tarde conocida como nueva neumonía por coronavirus (NCP), era causada por un nuevo coronavirus ${ }^{\mathrm{I}}$. La Organización Mundial de la Salud (OMS) nombró oficialmente la enfermedad 'COVID-I9' y el Comité Internacional de Taxonomía de Virus nombró al virus "coronavirus 2 del síndrome respiratorio agudo severo" (SARS-CoV-2) ${ }^{2}$. $\mathrm{Al}$ momento de la preparación de este manuscrito se han presentado en el mundo io millones de casos confirmados de COVID-I9, incluidas 500.00o muertes, según el centro de estadísticas de John Hopkins Hospital (https:// coronavirus.jhu.edu/map.html). Aunque no hay cifras oficiales, se sabe de trabajadores de salud contagiados y muertos a causa del virus, lo que hace que todas las medidas de protección deban extremarse.

\section{Objetivo}

Con este documento se pretende presentar a los cirujanos una técnica efectiva para el drenaje de neumotórax en pacientes con COVID-i9, que garantice un procedimiento seguro para el paciente, resolviendo de manera rápida su condición para mejorar la función ventilatoria, así como una técnica quirúrgica que minimice la exposición del personal de salud a los aerosoles contaminantes provenientes del enfermo.

\section{Generalidades}

\section{Transmisión de SARS-CoV-2}

Estudios epidemiológicos previos han demostrado que existen tres factores involucrados en la propagación viral: fuente de infección, vía de transmisión y susceptibilidad.

Fuente de infección: Los murciélagos se consideran los huéspedes naturales del SARS-CoV-2 y se cree que los pangolines y las serpientes son huéspedes intermedios. Aunque hasta la fecha no hay estudios que hayan aclarado completamente el posible huésped natural y el huésped intermedio del SARS-CoV-2, la evidencia adecuada muestra que este virus podría provenir de animales salvajes. En la actualidad, se considera 
que la principal fuente de infección del SARSCoV-2 son los pacientes con COVID-I9, sin embargo, sigue debatiéndose si estos pacientes son infecciosos durante el período de incubación '

Vía de Transmisión: Las gotas y el contacto cercano son las rutas más comunes de transmisión del SARS-CoV-2, pero la transmisión por aerosol puede ser otra ruta. Además, los investigadores han detectado SARS-CoV-2 en muestras de heces, tracto gastrointestinal, saliva y orina ${ }^{\mathrm{I}}$.

Susceptibilidad: Un informe de investigación epidemiológica publicó que las personas de edad avanzada son más susceptibles al SARSCoV-2 (edad promedio de muerte 75 años) y la mayoría de los pacientes que murieron tenían comorbilidades o antecedentes de cirugía antes del ingreso ${ }^{3}$.

\section{Neumotórax en paciente con COVID-19}

En pacientes con neumonía por SARS-CoV-2 existe una mayor probabilidad de desarrollar neumotórax, tanto espontáneo como secundario a ventilación mecánica. Se ha considerado que en estos pacientes el riesgo de neumotórax es del I \% ${ }^{4,5}$. Los alvéolos pueden ser propensos a romperse debido a una lesión alveolar difusa causada por el SARS-CoV-2 ${ }^{6}$ y la ruptura alveolar causa fugas que pueden resultar en neumotórax o enfisema subcutáneo ${ }^{7}$. En pacientes con Enfermedad Pulmonar Obstructiva Crónica (EPOC) el aumento a largo plazo de la presión alveolar, la disminución del suministro de sangre capilar alveolar y el deterioro de la nutrición del tejido pulmonar, debilitan la elasticidad y la tolerancia de la pared alveolar, haciendo más susceptibles a los pacientes con COVID-19 a desarrollar neumotórax ${ }^{8}$.

El neumotórax, el enfisema mediastínico y el enfisema subcutáneo son complicaciones bien conocidas de la ventilación mecánica ${ }^{9}$, debido a que al aumentar la presión dentro de las vías respiratorias se puede causar ruptura de los alvéolos, con formación de enfisema intersticial y creación de ampollas subpleurales, cuya ruptura ocasiona neumotórax. Al mismo tiempo, el gas viaja a traves del esqueleto axial peribroncovascular, causando neumomediastino ${ }^{\mathrm{IO}}$.

\section{Estado del arte Catéter pleural versus tubo de tórax.}

Aunque un pequeño neumotórax espontáneo puede resolverse sin tratamiento, para los pacientes sintomáticos es necesaria la extracción del aire mediante aspiración o drenaje con un catéter pleural (CP) o un tubo de tórax (TT) ${ }^{\text {II }}$, sin embargo, sigue siendo controvertido cuál usar. Por ejemplo, el consenso de Delphi del American College of Chest Physicians ${ }^{12}$ recomienda usar un TT (I6 Fr - 28 Fr) para tratar el neumotórax espontáneo primario y secundario; en contraste, la British Thoracic Society ya no recomienda el uso de TT para neumotórax espontáneo primario y secundario ".

Aunque el drenaje con TT ha sido el tratamiento de elección en pacientes con neumotórax durante décadas, hay un cambio de paradigma hacia el uso más rutinario de CP para manejar el neumotórax. Las ventajas del CP es su menor calibre, lo que permite un abordaje minimamente invasivo y una mayor comodidad para el paciente. Algunos estudios han sugerido que el drenaje con CP ahorra $\operatorname{costos}^{13-15}$ y puede ser un enfoque de tratamiento razonable para el primer episodio de neumotórax espontáneo grande ${ }^{15,16}$, definido según las directrices de British Thoracic Society como aquel que presenta dehiscencia pulmonar en toda la altura de la pared lateral del tórax ${ }^{17}$.

En general, el aire tiene una viscosidad mínima, por lo tanto, un CP de pequeño calibre puede ser suficiente para la mayoría de las fugas de aire resultantes de la fístula alveolo-pleural pura, independientemente de la clasificación del neumotórax. Por eso, el TT se puede reservar para el neumotórax refractario y los escenarios urgentes ${ }^{\mathrm{I}, 19}$.

En un meta-análisis que incluyó 875 pacientes ${ }^{20}$, la tasa de éxito fue similar en los dos grupos con CP $(79,84 \%)$ y TT $(82,87 \%)$, con OR de 0,99 $\left(\mathrm{IC}_{95 \%}\right.$ O,93-I,05; $I^{2}=0$ \%). Específicamente, el drenaje del neumotórax espontáneo con CP se asoció con una tasa de complicaciones, una duración del drenaje y una estancia hospitalaria significativamente menor que el drenaje con 
TT. En conjunto, los resultados del metaanálisis sugieren que el drenaje con CP puede considerarse como la opción de tratamiento inicial para pacientes con neumotórax espontáneo primario o secundario.

\section{Uso de filtros y soluciones con cloro}

Una reciente publicación del Royal College of Physicians ${ }^{21}$ mostró un experimento usando un filtro antiviral en la salida del reservorio de la trampa de agua, para mitigar el riesgo causado por la generación de aerosoles en pacientes con COVID-I9 sometidos a drenaje pleural. Se utilizó un filtro desechable de uso común en los circuitos de la máquina de anestesia, clasificado con un poder de filtración $>99,99 \%$ de eficiencia (Clear-Guard ${ }^{\mathrm{TM}} 3$ filtro respiratorio, Intersurgical Ltda, Madrid - España), que se unió por un conector recto de $22 \mathrm{~mm}$ a $6 \mathrm{~mm}$.

Para demostrar la reducción en la producción de emisiones de aerosoles se añadió tinte de fluoresceína al agua de la trampa usada rutinariamente, el drenaje pleural fue conectado al aire ambiente, una tarjeta negra fue colocada 3 $\mathrm{cm}$ por encima del respiradero de la trampa y se tomaron fotos bajo luz UV después de 2 horas. El experimento se repitió sin y con el filtro adjunto y las fotografías tomadas demuestran emisiones de aerosol y gotitas de la trampa cuando el filtro no es utilizado.

Por otra parte, una reciente publicación de Pieracci y colaboradores ${ }^{22}$, brinda recomendaciones adicionales para evitar la propagación de aerosoles, como agregar hipoclorito de sodio diluido a la cámara de sellado de agua en lugar de agua sola. Una relación de dilución típica es I:50, utilizando una parte de hipoclorito de sodio al $5,25 \%-6,15 \%$ por 50 partes de agua. Dado que la mayoría de los sistemas de drenaje para sonda torácica disponibles comercialmente contienen un volumen de cámara de sellado de agua de 45 a $60 \mathrm{ml}$, se puede agregar $\mathrm{I} \mathrm{ml}$ de cloro a 50 $\mathrm{ml}$ de agua. $\mathrm{Y}$ además conectar un filtro viral en línea de salida, ya sea que el sistema vaya a ser conectado a succión o no.

\section{Válvulas de Hemlich}

La válvula de Heimlich es un dispositivo portátil unidireccional que fue diseñado para usarse como un procedimiento de drenaje para evitar la necesidad de succión intrapleural después de la toracotomía ${ }^{23}$. Ha sido muy útil en el tratamiento ambulatorio de pacientes con fuga de aire prolongada por diversas causas ${ }^{24}$, y también se ha utilizado en el tratamiento de emergencia del neumotórax en los frentes de batalla ${ }^{25}$.

La válvula tiene dos boquillas, la boquilla de entrada que permite que el aire pase por la válvula a través del tubo de drenaje torácico conectado a ella, y la boquilla de salida que permite que el aire pase al ambiente o un dispositivo colector. Su principal utilidad es reemplazar el sistema de drenaje pleural (trampa de agua), pero en general, requiere la inserción de un tubo de tórax al cual posteriormente se conecta ${ }^{26}$. En el momento actual, no se recomienda su inserción por el riesgo de generación de aerosoles. También podría adaptarse a un catéter mediante un conector especial, sin embargo, la principal limitación para su uso en pacientes con COVID-I9, es el control del aire que sale de la válvula, ya que se dificulta su conexión a un filtro viral o a un sistema de trampa con hipoclorito, lo cual se consigue de manera mas eficaz con el sistema de catéter conectado a trampa de agua y filtro de salida.

\section{Aspectos técnicos}

\section{Lista de Chequeo del procedimiento}

Antes de iniciar el procedimiento deben llevarse a cabo las siguientes acciones:

- Identificación adecuada del paciente.

- Verificación de consentimiento informado para realizar el procedimiento, firmado por el paciente o su representante; excepto en casos de urgencia vital.

- Confirmación del lado correcto afectado por el neumotórax, revisando nuevamente la radiografía de tórax, idealmente en compañía de un par. 
- Chequeo de elementos de protección personal (EPP) completos y en perfecto estado.

- Verificación de los insumos necesarios para el procedimiento.

- Conocimiento completo del plan quirúrgico por parte de las personas comprometidas (usualmente el Cirujano y un Terapista Respiratorio, o el Fisioterapeuta encargado de la ventilación mecánica en caso de estar en la Unidad de Cuidado Intensivo).

- En caso de pacientes bajo ventilación mecánica, solicitar el mayor nivel de sedación y relajación posible para evitar tos durante el procedimiento.

- Ingrese solo el equipo esencial a la habitación o cubículo, incluido un exceso de suministro de cualquier medicamento que se necesite. Tenga a mano el equipo potencialmente necesario. Es importante evitar demoras o interrupciones después de comenzar el procedimiento debido a la falta de equipo o medicamentos sedantes.

- Asegure la presencia de un filtro viral de partículas de alta eficiencia (HEPA) en el ventilador y también en el equipo de succión.

\section{Insumos y equipo}

- Bandeja de pequeña cirugía que incluya:

- Mango y hoja de bisturí

- Pinza de Kelly

- Portaagujas

- Pinza de disección

- Sutura para fijación del catéter.

- Anestésico local y jeringa para su aplicación.

- Catéter multipropósito tipo Pig Tail de I2 a I6 Fr., con introductor con punzón y endocánula que incluya conector para sistema de drenaje (figura I).

- Sistema de trampa de agua, completamente configurado, con solución de agua e hipoclorito y filtro de salida (figura 2).

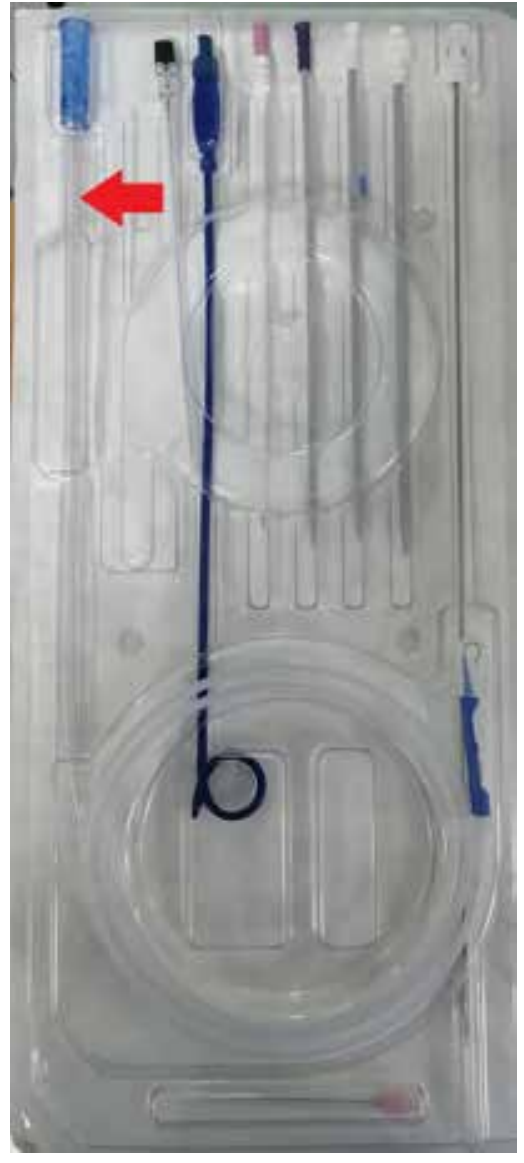

Figura 1. Catéter multipropósito tipo Pig Tail con introductor, endocánula y conector para sistema de drenaje (flecha roja).

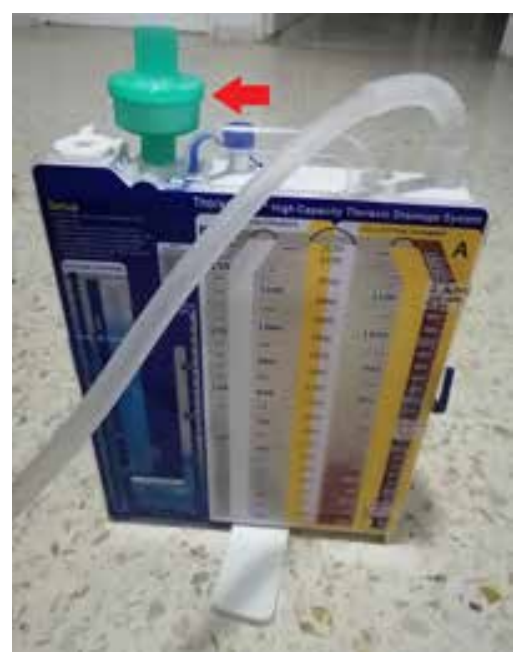

Figura 2. Sistema de trampa de agua con solución de agua e hipoclorito y filtro de salida (flecha roja) 
- Paquete de ropa estéril, incluyendo campos quirúrgicos.

\section{Técnica Quirúrgica}

- Realice una higiene de manos estándar y utilice una técnica de doble guante, que se ha recomendado para reducir el riesgo de transferencia viral durante la retirada de los $\mathrm{EPP}^{27}$. Use ropa quirúrgica y una bata resistente a los fluidos, gorro quirúrgico, máscara $\mathrm{N}-95$ o Pioo o superior y protección ocular completa ${ }^{28}$ (figura 3 ).

- Posicione al paciente exponiendo el hemitórax comprometido.

- Realice medidas de asepsia y antisepsia de acuerdo con protocolo de su institución.

- Solicite a quien lo esté acompañando en el cubículo o habitación que despliegue el paquete de ropa estéril sobre el vientre del paciente.

- Retire el par de guantes externos con los que acaba de hacer el lavado.

- Tome del paquete la bata estéril, vístase con ella y pida ayuda para el amarre en la espalda.

- Colóquese un nuevo par de guantes estériles.

- Cubra completamente el paciente y la cama después de la preparación estéril del tórax para evitar cualquier contaminación de la cama, la almohada, las sábanas o el equipo (figura 4).

- Coloque los instrumentos en una bandeja sobre el paciente si este está completamente dormido o sobre una mesa plana para evitar que el equipo ruede o se caiga de la cama si el paciente está despierto (figura 5).

- Pida a su acompañante que le entregue con técnica aséptica el paquete con el catéter y sus aditamentos y dispóngalo sobre los campos estériles.

- Pida que le entreguen el extremo estéril de la manguera del sistema de drenaje pleural,

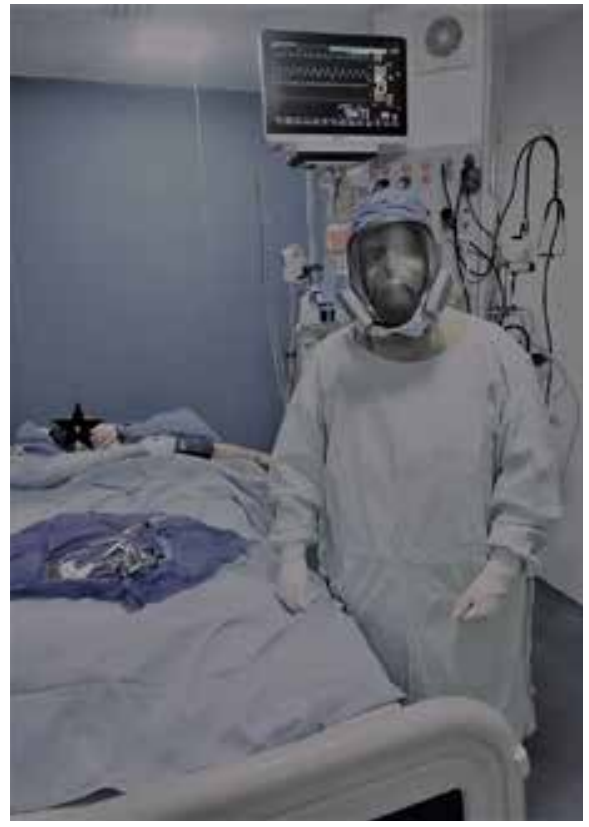

Figura 3. Cirujano usando ropa quirúrgica y los elementos de protección personal completos

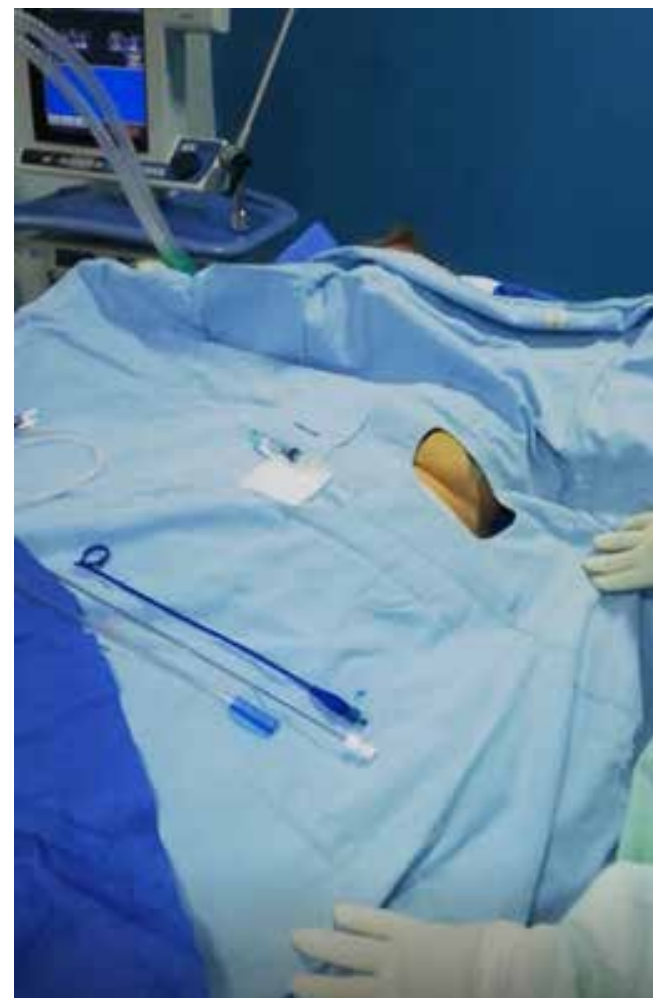

Figura 4. Con la ropa quirúrgica estéril se cubre completamente el paciente y la cama para evitar cualquier contaminación. 


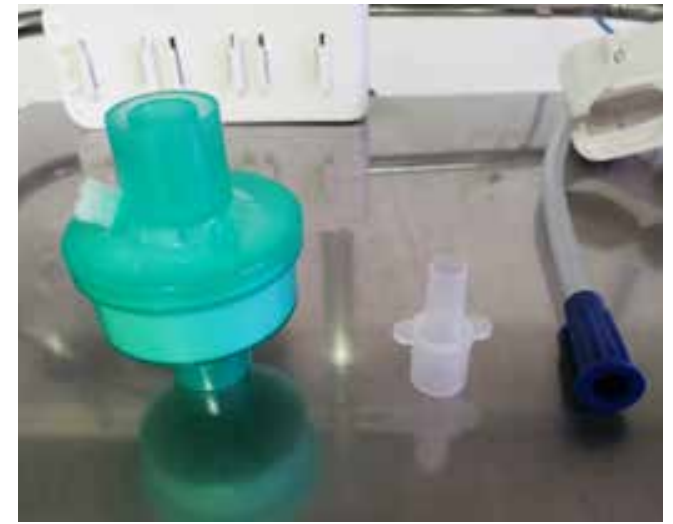

Figura 5. Filtro y adaptador para sistema conexión a succión.

conéctelo al adaptador del catéter y déjelo sobre el campo estéril, de forma que no vaya a resbalar y caer (figura 6).

- Arme el sistema de catéter estirando su punta e insertando la endocánula, luego introduzca en ella el punzón y asegure que el sistema quede completamente cerrado y hermético (puede estar seguro de que lo ha hecho correctamente si la punta del punzón aparece en la punta del catéter).

- Deje el catéter armado cerca de su alcance.

- Administre anestésico local en el sitio escogido para la punción, idealmente entre el $5^{\circ}$ y el $6^{\circ}$ espacio intercostal, aunque esto puede variar dependiendo del paciente. Es posible verificar la presencia del neumotórax durante la infiltración con el anestésico. Guarde i a 2 cc de anestésico para humedecer el catéter y facilitar su entrada.

- Practique una pequeña incisión con la punta del bisturí, de aproximadamente $3 \mathrm{~mm}$. Por ningún motivo intente realizar trayecto con pinzas $u$ otro instrumento.

- Sujete firmemente el catéter humedecido antes de la inserción.

- Inserte con movimientos suaves el catéter hasta tener la percepción de haber ingresado al espacio pleural (figura 7).

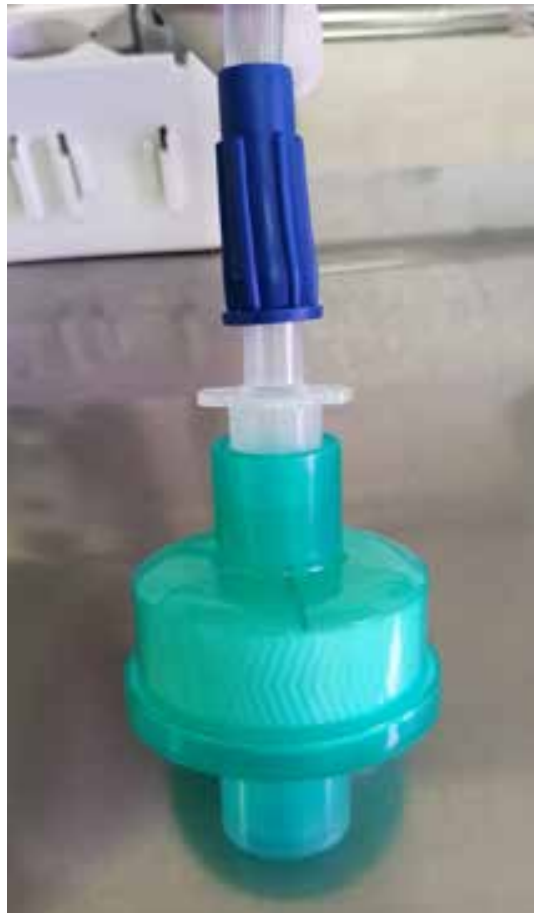

Figura 6. Filtro conectado a sistema de succión por medio del adaptador

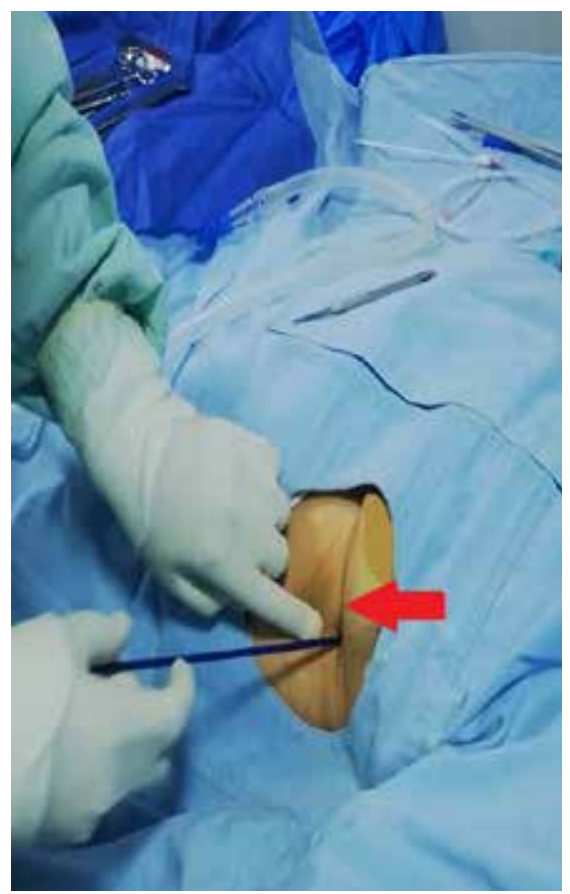

Figura 7. Inserción del catéter con movimientos suaves hasta ingresar al espacio pleural. 
- Desasegure el introductor y retírelo suavemente, ocluyendo con el dedo en el momento de retirarlo por completo, colocando una jeringa que cierre el sistema y permita verificar la ubicación de la punta en el espacio pleural, al obtener de manera fácil aire con la aspiración.

- Deslice suavemente el catéter hacia la cavidad pleural, al mismo tiempo que retira la endocanula metálica y la jeringa. Antes de retirarla por completo, ocluya el catéter con una pinza de Kelly, sin comprometer su estructura, y después termine la extracción de la endocanula.

- Si usa un campo quirúrgico con fenestra o "campo de ojo" retírelo en este momento.

- Conecte el catéter mediante el conector al sistema de drenaje torácico previamente preparado (figura 8).

- Asegúrese de que el catéter no se desprenda del sistema de drenaje.

- Arme el sistema de cola de cerdo (pig tail) mediante la tracción de los hilos dispuestos para ellos y fíjelos en la ranura respectiva.

- Fije el catéter a la piel con sutura.

- Realice aseo de la zona quirúrgica y verifique el adecuado funcionamiento del drenaje.

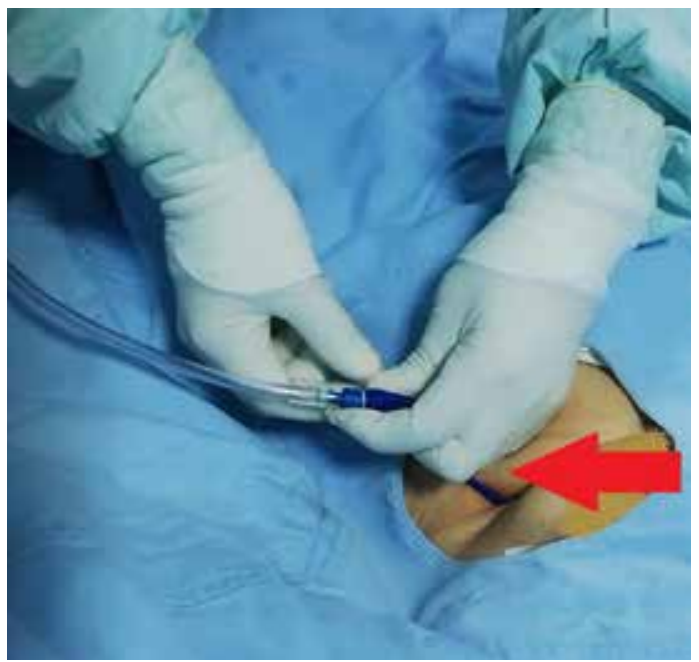

Figura 8. Se conecta el catéter pleural al sistema de drenaje torácico utilizando el conector.
- Disponga el material desechable y los campos quirúrgicos en sus respectivos recipientes.

- Retírese los EPP según lo recomendado por los CDC ${ }^{29}$.

- Solicite una radiografía de tórax de control y no considere haber terminado el procedimiento hasta no revisarla personalmente.

Puede ver el procedimiento completo en el video complementario a través del siguiente enlace https://youtu.be/KQcwNG-oIF8

\section{Conclusiones}

El neumotórax es una entidad frecuente a la que se ve enfrentado el cirujano, y en el estado actual de pandemia por COVID-I9, es probable que varios pacientes presenten neumotórax secundario al compromiso pulmonar o al tratamiento con ventilación mecánica. Es necesario tomar todas las medidas posibles para minimizar los riesgos de exposición durante procedimientos generadores de aerosoles. La toracostomía con tubo de tórax realizada de manera tradicional constituye, sin lugar a dudas, una fuente generadora de aerosoles. Existen estudios que muestran igual eficacia en el drenaje de neumotórax con catéteres de menor diámetro. La inserción de un catéter pleural, con algunas modificaciones en su técnica, como las que presentamos para mantener el sistema siempre cerrado, puede evitar la dispersión de aerosoles y disminuir el riesgo de contagio para el personal de salud. La inserción de un catéter pleural para drenaje de neumotórax apegado al protocolo que sugerimos requiere la participación, y por tanto la exposición, de un mínimo de trabajadores de la salud. Idealmente, deben hacerse ensayos controlados aleatorios para comparar el uso de catéter pleural versus el tubo de tórax entre diferentes subgrupos de pacientes con neumotórax, para mejorar la atención clínica y el manejo de estos pacientes.

\section{Cumplimiento de normas éticas}

Consentimiento informado: Esta publicación es una revisión de la literatura y presenta la experiencia de un grupo de profesionales en la 
práctica de un procedimiento quirúrgico, sin poner en riesgo a los pacientes, por lo que no hay necesidad de un consentimiento informado adicional. En las imágenes ilustrativas se protege la identidad de los pacientes e instituciones.

Declaración de conflicto de intereses: Los autores no declaran ningún conflicto de interés.

Fuentes de financiación: El trabajo fue realizado enteramente con recursos propios de los autores.

\section{Referencias}

I. Lisheng W, Yiru W, Dawei Y, Qingquan L. Review of the 2019 novel coronavirus (SARS-CoV-2) based on current evidence. Int J Antimicrob Agents. 2020 Jun; 55:I05948. Published online 2020 Mar 19. https://doi.org/I0.IoI6/j.ijantimicag.2020.I05948

2. Chaolin H, Yeming W, Xingwang L, Lili R, Jianping $\mathrm{Z}$, Yi H, et al. Clinical characteristics of patients infected with novel 2019 coronavirus in Wuhan. Lancet 2020;395:497-506. https://doi.org/IO.IoI6/ SoI40-6736 (20) 30183-5

3. Weier W, Jianming T, Phangqiang W. Updated understanding of the outbreak of 2019 novel coronavirus (2019 $\mathrm{nCoV}$ ) in Wuhan, China. J Med Virol. 2020;92:44I-7. https://doi.org/IO.IOO2/jmv.25689

4. Xiang C, Wu G. SARS-CoV-2 pneumonia with subcutaneous emphysema, mediastinal emphysema, and pneumothorax. Medicine 2020;99:e20208. https://doi.org/I0.I097/MD.0000000000020208

5. Chen N, Zhou M, Dong X, Qu J, Gong F, Han Y, et al. Epidemiological and clinical characteristics of 99 cases of 2019 novel coronavirus pneumonia in Wuhan, China: a descriptive study. Lancet. 2020;395:507-I3. https://doi.org/IO.IOI6/SoI40-6736(20)302II-7

6. Xu Z, Shi L, Wang Y, Zhang J, Huang L, Zhang C, et al. Pathological findings of COVID-I9 associated with acute respiratory distress syndrome. Lancet Respir Med. 2020;8:420-2. https://doi.org/I0.IOI6/S2213-2600(20)30076-X

7. Sun R, Liu H, Wang X. Mediastinal emphysema, giant bulla, and pneumothorax developed during the course of COVID-I9 pneumonia. Korean J Radiol. 2020 March. https://doi.org/IO.3348/kjr.2020.oI8o

8. Gadre SK, Duggal A, Mireles-Cabodevila E, Krishnan $\mathrm{S}$, Wang XF, Zell K, et al. Acute respiratory failure requiring mechanical ventilation in severe chronic obstructive pulmonary disease (COPD). Medicine. 2018;97:e0487. https://doi.org/I0.I097/MD.oooooooooooI0487
9. Badaoui R, Thiel V, Perret C, Popov I, Dupont H. Bilateral pneumothorax, cervicofacial and mediastinal emphysema after surgical tracheostomy. Ann Fr Anesth Reanim. 2013;32:718-20. https://doi.org/I0.IOI6/j.annfar.20I3.07.815

Io. Sonobe S, Inoue S, Nishiwada T, Egawa J, Kawaguchi M. A case of subcutaneous emphysema/mediastinal emphysema during the use of humidified highflow nasal cannula. JA Clin Rep. 2019;5:85. https://doi.org/IO.II86/s4098I-0I9-0305-3

II. MacDuff A, Arnold A, Harvey J, BTS Pleural Disease Guideline Group. Management of spontaneous pneumothorax: British Thoracic Society Pleural Disease Guideline 20I0. Thorax. 2010;65(suppl 2):iir8-iizI. https://doi.org/IO.II36/thx.20I0.136986

I2. Baumann MH, Strange C, Heffner JE, Light R, Kirby TJ, Klein J, et al. Management of spontaneous pneumothorax: an American College of Chest Physicians Delphi consensus statement. Chest. 200I;II9:590-602. https://doi.org/IO.I378/chest.II9.2.590

I3. M, Alexander P, Driesen P, Slabbynck H, Verstraeten A. Manual aspiration versus chest tube drainage in first episodes of primary spontaneous pneumothorax: A multicenter, prospective, randomized pilot study. Am J Respir Crit Care Med. 2002;165:I240-4. https://doi.org/I0.II64/rccm.200III-078OC.

I4. Ayed AK, Chandrasekaran C, Sukumar M. Aspiration versus tube drainage in primary spontaneous pneumothorax: A randomised study. Eur Respir J. 2006;27:477-82. https://doi.org/I0.II83/09031936.06.00091505

I5. Massongo M, Leroy S, Scherpereel A, Vaniet F, Dhalluin X, Chahine B, et al. Outpatient management of primary spontaneous pneumothorax:a prospective study. Eur Respir J. 2014;43:582-90. https://doi.org/IO.II83/09031936.00I79II2

I6. Voisin F, Sohier L, Rochas Y, Kerjou M, Ricordel C, Belleguic $\mathrm{C}$, et al. Ambulatory management of large spontaneous pneumothorax with pigtail catheters. Ann Emerg Med. 2014;64: 222-8.

https://doi.org/I0.IoI6/j.annemergmed.2013.12.017

I7. De Leyn P, Lismonde M, Ninane V, Noppen M, Slabbynck H, Van Meerhaeghe A, et al. Guidelines belgian society of pneumology. Guidelines on the management of spontaneous pneumothorax. Acta Chir Belg. 2005;105:265-7. https://doi.org/IO.IO80/oool5458.2005.II6797I4

I8. Inaba K, Lustenberger T, Recinos G, Georgiou C, Velmahos GC, Brown C, et al. Does size matter? A prospective analysis of 28-32 versus 36-40 French chest tube size in trauma. J Trauma Acute Care Surg. 2012;72:422-7. https://doi.org/IO.I097/TA.oboI3e3I82452444 
I9. Vedam H, Barnes DJ. Comparison of large- and small-bore intercostal catheters in the management of spontaneous pneumothorax. Intern Med J. 2003;33:495-9. https://doi.org/I0.IO46/j.I445-5994.2003.00467.x

20. Chang SH, Kang YN, Chiu HY, Chiu YH. A Systematic review and meta-analysis comparing pigtail catheter and chest tube as the initial treatment for pneumothorax. Chest. 20I8;I53:I2OI-I2. https://doi.org/Io.IOI6/j.chest.20I8.oI.048

2I. Akhtar MR, Ricketts W, Fotheringham T. Use of an antiviral filter attached to a pleural drain bottle to prevent aerosol contamination with SARS-CoV-2. Clinical Medicine. 2020;20. https://doi.org/IO.786I/clinmed.2020-0246

22. Pieracci FM, Burlew CC, Spain D, Livingston DH, Bulger EM, Davis KA, et al Tube thoracostomy during the COVID-I9 pandemic: guidance and recommendations from the AAST Acute Care Surgery and Critical Care Committees Trauma Surg Acute Care Open. 2020;5:e0oo498.

https://doi.org/IO.II36/tsaco-2020-000498

23. Bernstein A, Waqaruddin M, Shah M. Management of spontaneous pneumothorax using a Heimlich flutter valve. Thorax. 1973;28:386-9.
24. Edenborough FP, Hussain I, Stableforth DE. Use of a Heimlich flutter valve for pneumothorax in cystic fibrosis. Thorax. 1994;49:II78-9.

25. Fox B. Use of the Heimlich flutter valve for chest drainage in battle casualties. Aust N Z J Surg. 1967;37:I45-7.

26. Gogakos A, Barbetakis N, Lazaridis G, Papaiwannou A, Karavergou A, Lampaki S, et al. Heimlich valve and pneumothorax, Ann Transl Med. 2015;3:54. https://doi.org/I0.3978/j.issn.2305-5839.2015.03.25

27. Casanova LM, Rutala WA, Weber DJ, Sobsey MD. Effect of single- versus double-gloving on virus transfer to health care workers' skin and clothing during removal of personal protective equipment. Am J Infect Control 2012;40:369-74. https://doi.org/Io.IoI6/j.ajic.20II.04.324

28. Anesthesia Patient Safety Foundation. Perioperative considerations for the 2019 novel coronavirus (COVID-I9). Fecha de consulta: I9 de marzo de 2020. Disponible en:

https://www.apsf.org/news-updates/perioperative-considerations-for-the-20I9-novel-coronavirus-covid-19 /

29. Centers for Disease Control and Prevention. Coronavirus (COVID-I9). Fecha de consulta: I9 de marzo de 2020. Disponible en:

https://www.cdc.gov/coronavirus/20I9-ncov/index.html 